\title{
CALCULATION AND STUDY OF THE MAGNETIC FIELD OF THE STATOR WINDING OF A TURBINE GENERATOR
}

\author{
Gulzoda Mustafakulova ${ }^{1}$, Akmal Egamov $^{2}$, Utkir Mirkhonov ${ }^{3}$, Jasurbek Nizamov $^{4}$ \\ ${ }^{1}$ Tashkent State Technical University, Department of Electrical machine, Tashkent, 100095, Uzbekistan \\ ${ }^{2}$ Tashkent State Technical University, Department of Electrical machine, Tashkent, 100095, Uzbekistan \\ ${ }^{3}$ Bukhara Engineering Technological Institute, Department of Energy audit, Bukhara, 200117, Uzbekistan \\ ${ }^{4}$ Tashkent State Technical University, Department of Electrical machine, Tashkent, 100095, Uzbekistan
}

\begin{abstract}
An analytical method is presented for calculating the electromagnetic field of the stator winding of an alternating current machine, a turbine generator by solving the Laplace equation, first for a point conductor with a current $i$, by the method of separating variables when representing the space of the machine location consisting of five regions. The purpose of the work is to show that for all three components of the air gap field created by the winding, the magnetic circuit is common, but the magnetic circuits are different for each of them.
\end{abstract}

\section{Introduction}

Of the currently existing analytical methods for solving the field equation, we used the method of direct solution, i.e. solution of the Laplace equation by the method of separation of variables. It is known [1] that the method of direct solution of the field equations is reduced to finding a potential function that satisfies the Laplace or Poisson equations, as well as specified boundary and other conditions that determine the field in a particular investigated area of space where an $\mathrm{AC}$ electric machine is located [2].

\section{Analytical method for calculating the electromagnetic field of the stator winding of a turbine generator}

An analytical method for calculating the electromagnetic field of the stator winding of an alternating current turbine generator (TG) by solving the Laplace equation first for a point conductor with a current $i$, by the separation of variables method when representing the space of the machine location consisting of five regions [3] (Fig. 1):

1. Outer region $\rho>d$ with index 0 and magnetic permeability $\mu_{0}=4 \pi 10^{-7} \mathrm{H} / \mathrm{m}$;

2. Stator area $d>\rho>c$ with index 1 and permeability $\mu_{1}$;

3. Air gap $c>\rho>b$ with index $\delta$ and permeability $\mu_{0}$;

4. Rotor area $b>\rho>a$ with index 2 and permeability $\mu_{2}$;

5. Internal area $a>\rho>0$ with index 3 and permeability $\mu_{0}$.

Since there is no volume distribution of the current density in this two-dimensional model, the magnetic field can be characterized by a scalar magnetic potential
$\mathrm{V}$ and in a cylindrical coordinate system satisfies the Laplace differential equation in partial derivatives

$$
\frac{\partial}{\partial \rho}\left(\rho \frac{\partial V}{\partial \rho}\right)+\frac{1}{\rho} \frac{\partial^{2} V}{\partial \varphi^{2}}=0
$$

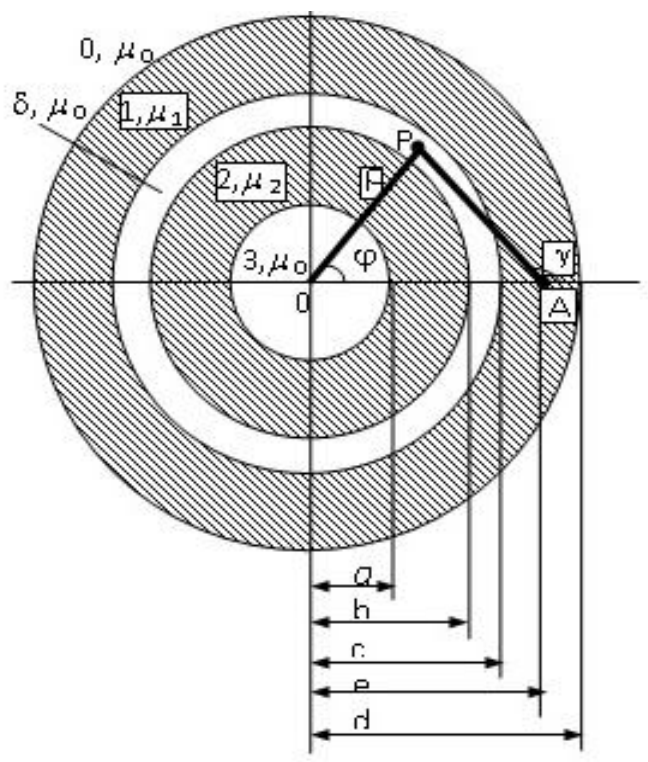

Fig. 1. Space for the location of electrical machines

The expression for the magnetic field strength in the air gap created by a three-phase two-layer stator winding with integer $q_{l}$ when a sinusoidal symmetric three-phase current with a frequency $f_{l}$ flows through it will have the form 


$$
\begin{aligned}
& \mathrm{H}_{\mathrm{T}}=4 \mathrm{pw}_{\mathrm{\kappa} 1} \mathrm{q}_{1} \sum_{\mathrm{n}=1}^{\infty} \mathrm{K}_{\mathrm{n}} \mathrm{K}_{\mathrm{oб} \mathrm{n}} \mathrm{K}_{\mathrm{pqn}} * \\
& {\left[\sin \mathrm{n}\left(\varphi-\frac{2 \mathrm{p}-1}{\mathrm{p}} \frac{\pi}{2}\right) \sin \left(\omega_{1} \mathrm{t}+\frac{2 \pi}{3}\right)+\right.} \\
& +\sin \left(\varphi-\frac{2 p-1}{p} \frac{\pi}{2}-\frac{2 \pi}{3 p}\right) \sin \left(\omega_{1} t-\frac{2 \pi}{3}\right)+ \\
& \left.+\sin \mathrm{n}\left(\varphi-\frac{2 p-1}{p} \frac{\pi}{2}-\frac{4 \pi}{3 p}\right) \sin \omega_{1} t\right]
\end{aligned}
$$

In Figure 2 shows the distribution curves of the stator bore circumference of the magnetic inductions of the individual components of the resulting air gap field created by the two-layer stator winding of the TVV-2002 type turbine generator, as well as the distribution of the sides of the coils for times $t=1 / 600$ and $1 / 300 \mathrm{~s}$ within one pole division. When studying the magnetic field in the air gap created by one or another winding of an implicit-pole synchronous AC machine, the resulting field is conventionally divided into three components:

1. The main field with magnetic induction $B_{p}$;

2. The field of scattering along the crowns of teeth with induction $\mathrm{B}_{\mathrm{Kz}}$;

3. Field of belt scattering with induction $B_{\text {пя. }}$.
The main field is a field with an order equal to the number of pairs of poles of the machine, and the scattering field along the crown of the teeth is the sum of all spatial harmonic fields of the air gap with an order starting from the subdental $\mathrm{n} \Pi \mathrm{z}$ and higher. The value of $\mathrm{n} \Pi \mathrm{z}$ can be found from the expression $\mathrm{n}_{\mathrm{nz}}=\left(Z_{1} / 2\right)-\mathrm{p}$, where $Z_{1}$ is the number of stator slots [4-5].

As seen from Fig. 2, the curve of the stray field along the crowns of the teeth is practically symmetric about the abscissa axis, and each pair of poles is located symmetrically relative to the axis of the corresponding groove with a current and the magnitude of the magnetic induction of this field, other things being equal, is proportional to the value of the total current of the groove, and the magnetic field lines of one pair of poles cover only one groove with current and the magnetic poles are located symmetrically about the axis of each groove with a total current other than zero.

With the expiration of time, i.e. as the star of the phase current vectors turns, the axis of each pair of poles remains stationary relative to the winding, coinciding with the axis of the corresponding slot, and only the value of the magnetic induction changes almost in proportion to the value of the total slot current.

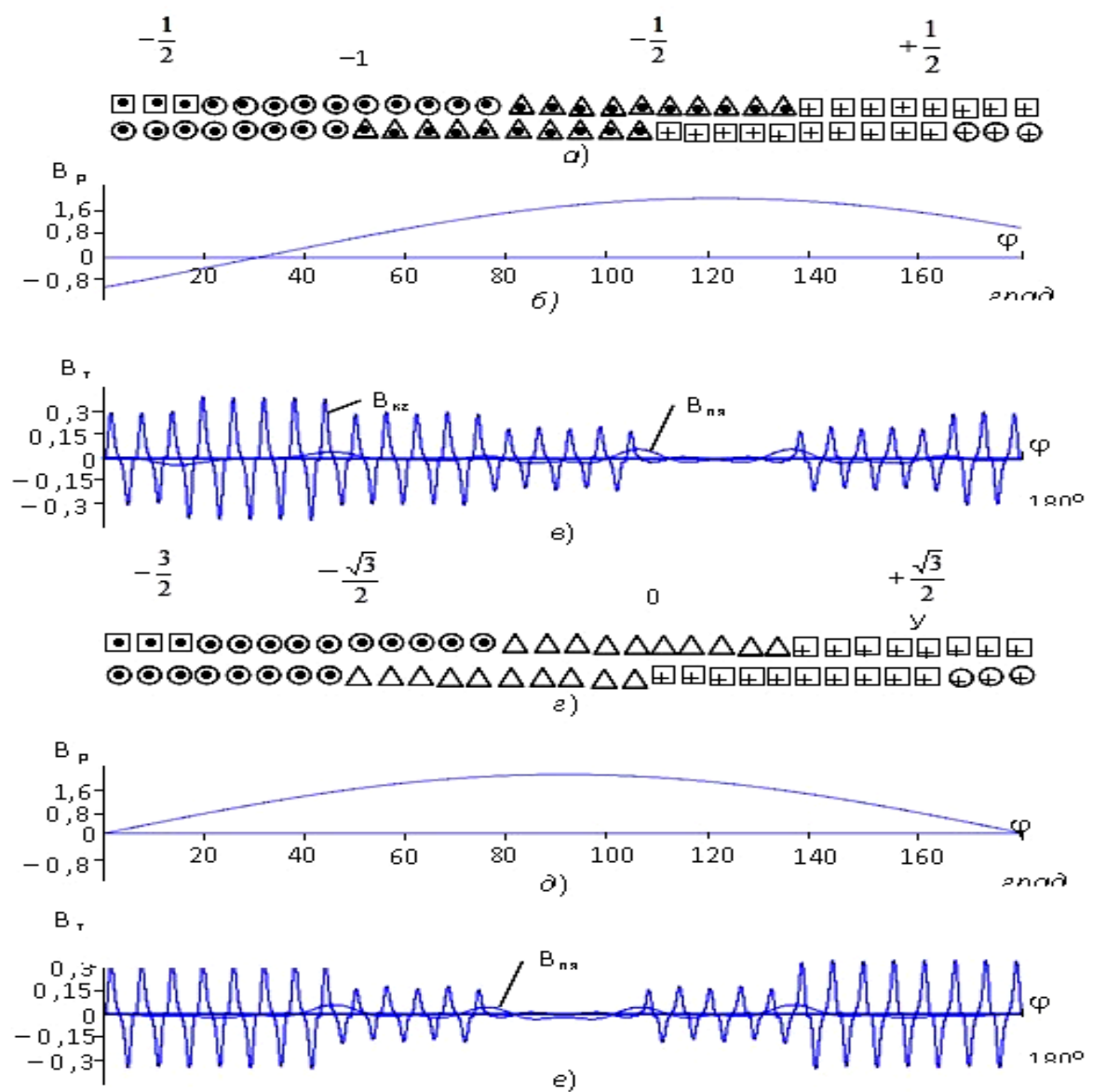

Fig. 2. Fig. 2. The distribution pattern of the component of the magnetic induction of the stator winding 


\section{Conclusion}

The belt component of the field of differential scattering of the armature winding due to the shortening of the pitch of the distribution of the coils in the grooves by an order of magnitude or more may be less scattering along the crowns of the teeth,

- When calculating the field, the equivalent values of the magnetic permeabilities of the stator $\mu_{1}$ and rotor $\mu_{2}$, found separately for each component of the air gap field, should be used, which correspond to the actual operating mode of the machine,

- For all three components of the air gap field created by the winding, the magnetic circuit is common, but the magnetic circuits are different for each of them.

\section{References}

1. Abramov, A. I. Proyektirovaniye turbogeneratorov / A. I. Abramov, V. I. Izvekov, N. A. Serixin. - M.: Vissh. shk., 1990. - $336 \mathrm{~s}$.

2. Olimjon Toirov, Utkir Mirkhonov, Gulzoda Mustafakulova Principles for Controlling the Excitation of Synchronous Motors of the Compressor Installation // International Journal of Advanced Research in Science, Engineering and Technology. - India, 2020.Vol.7, N5. P.13876-13881.

3. Demirchyan, K.S. Modelirovaniye magnitnix poley / K. S. Demirchyan. - L.: Energiya, 1974. - 288 s.

4. Danilevich, Ya.B. Chislennie metodi analiza elektricheskix mashin / Ya.B.Danilevich, A.V.Glazenko, A.A.Karimov i dr. - L.: Nauka, 1988. - 222 s.

5.Hoshimov, F.A., Bakhadirov, I.I., Erejepov, M., Djumamuratov, B. (2019) Development of method for normalizing electricity consumption E3S Web Conf 139 doi:10.1051/e3sconf/201913901074 